\title{
O Activity Based Costing ( $A B C)$ na Companhia de Eletricidade do Estado da Bahia (Coelba): fatores relevantes para implantação, o modelo e os resultados obtidos
}

\author{
Juliano Almeida de Faria \\ Mestrado em Contabilidade pela Universidade Federal da Bahia \\ Praça 13 de maio, 6, Centro, 40070-010 - Salvador, BA \\ julianoalmeida@ufba.br \\ Sonia Maria da Silva Gomes \\ Doutora em Engenharia de Produção pela Universidade Federal de Santa Catarina - UFSC \\ Professora da Universidade Federal da Bahia - UFBA \\ Praça 13 de maio, 6, Centro, 40070-010 - Salvador, BA \\ soniagomes3@gmail.com
}

O mundo evolui de forma cada vez mais rápida e, com isso, novas demandas das empresas surgem a todo o momento. Neste contexto, a contabilidade gerencial busca respostas para novas necessidades, sobretudo baseadas em informações de qualidade. A ideia básica do Activity-Based Costing (ABC), de que os recursos disponíveis são consumidos por atividades e estas são consumidas por produtos e serviços, representou uma proposta de tratar os custos indiretos com maior acuracidade, como forma alternativa no fornecimento de informações aos tomadores de decisão. O objetivo geral desta pesquisa foi verificar os fatores que contribuíram para que a Companhia de Eletricidade do Estado da Bahia Coelba - implantasse o $A B C$ e qual foi o modelo por ela adotado. Especificamente, buscou-se identificar os fatores iniciais que conduziram à escolha e adoção do $A B C$ e apresentar o modelo adotado e os resultados da aplicação do método. Este estudo caracteriza-se como qualitativo-descritivo no qual o estudo de caso foi adotado como procedimento de pesquisa e os dados foram obtidos através de entrevista não estruturada e aplicação de questionário. O principal fator para implantação foi a necessidade de redução de custos por meio de relatórios mais confiáveis e acurados. A Coelba adotou um modelo híbrido adaptado às próprias necessidades e características da empresa, porém fortemente baseado no modelo de Kaplan e Cooper (1998). Os resultados após dois anos de aplicação do método superam as expectativas iniciais, fato que sustenta a intenção da empresa em manter o uso do sistema. 
O Activity Based Costing ( $A B C$ ) na Companhia de Eletricidade do estado da Bahia (Coelba): fatores relevantes para implantação, o modelo e os resultados obtidos Juliano Almeida de Faria, Sonia Maria da Silva Gomes

the available resources are used by activities and these are used by products and services, represented a proposal to treat more accurately the indirect costs as an alternative way of providing information to those who take decisions. The general purpose of this research was to check the factors which contributed to the implementation of the model by Companhia de Eletricidade do Estado da Bahia Coelba -, and what was the model adopted by them. Specifically, it was intended to identify the initial factors which led to the choice and adoption of the $A B C$ and present the model adopted and the results of the implementation of this model. This study can be characterized as qualitative-descriptive, in which the case study was adopted as the procedure of research and the data was obtained from nonstructured interviews and a questionaire. The main reason to the implementation was the necessity of reducing the costs through more reliable and accurate reports. Coelba adopted a hybrid model adapted to its own necessities and characteristics but it was strongly based on the model of Kaplan and Cooper (1998). The results after two years of the implementation of the model exceeded the initial expectations, a fact that maintains the intention of the company of keeping on using the system.

Keywords: Activity-Based Costing (ABC). Costs. Electricity sector.

\section{CONSIDERAÇÕES INICIAIS}

O mundo evolui de forma cada vez mais rápida e fatores como o desenvolvimento tecnológico e internacionalização do comércio contribuem para isso, demandando das empresas flexibilidade para adaptação aos novos ambientes de negócio com rapidez e eficiência. A informação passou a ser um diferencial neste processo e, conseqüentemente, as organizações têm se empenhado em buscar inovações no processo de gestão e no aprimoramento de seus controles. Qualidade e preços mais baixos passaram a ser itens obrigatórios na maioria dos produtos ou serviços oferecidos ao mercado, tornando primordial a busca de fatores diferenciadores que agregassem valor aos produtos e reduzissem custos das operações.

No Brasil, o custeio $A B C$ aparece no mercado com uma abordagem diferenciada de apuração de custos baseando-se numa visão horizontal da empresa focando o custeio das atividades executadas pela empresa, independente de qual setor ou departamento utilize os recursos. A ideia básica do $A B C$ de que os recursos disponíveis são consumidos por atividades e estas são consumidas pelos produtos e serviços, representou uma proposta alternativa de tratar os custos indiretos com maior acuracidade desde que fossem relevantes para a empresa, como é o caso das empresas de distribuição de energia elétrica no Brasil. 
O Activity Based Costing ( $A B C$ ) na Companhia de Eletricidade do estado da Bahia (Coelba): fatores relevantes para implantação, o modelo e os resultados obtidos Juliano Almeida de Faria, Sonia Maria da Silva Gomes

O setor de fornecimento e distribuição de energia elétrica do país vem passando por intensas transformações. O marco principal ocorreu no ano de 1995, a partir do qual todas as concessões de serviços públicos, incluindo o setor elétrico, passaram a ser objeto de licitação competitiva. Com isso, o monopólio vigente no país por mais de trinta anos cedeu espaço à livre concorrência para as concessões, logo, o foco anterior na produção se transfere para o cliente, entre diversas alterações exigidas pelo governo. Foi criada a Agência Nacional de Energia Elétrica (ANEEL), órgão regulador responsável pela fiscalização das empresas que assumiram a responsabilidade de manter os serviços de distribuição de energia elétrica. Era preciso adequar-se ao novo ambiente de mercado, e desta forma ocorreram mudanças por parte das empresas participantes na forma de gerenciar e controlar seus recursos.

A Coelba não esteve alheia a este processo e entre diversas ações adotou o $A B C$, pois também precisou adequar-se ao novo ambiente caracterizado pela regulação, concorrência e competitividade entre as empresas do setor, formadas por capitais privados dos mais diversos países ou capitais públicos. Portanto, questiona-se neste artigo: Quais os fatores que contribuíram para a implantação do $A B C$, qual modelo adotado e que resultados são percebidos pela Companhia de Eletricidade do Estado da Bahia - Coelba?

A Coelba implantou o ABC e dispõe de um ambiente focado neste processo tornandoo propício ao estudo proposto. Entende-se que os efeitos de uma gestão de custos de qualidade podem contribuir para a perpetuação da empresa no mercado, podendo fornecer seus serviços a custos menores a toda a população do Estado da Bahia, considerando a importância da energia elétrica no contexto social. O preço pago pela energia elétrica (além dos serviços agregados a este fim) pode interferir em toda cadeia produtiva das empresas e diretamente na vida dos cidadãos. Trata-se de um estudo pioneiro no Estado da Bahia-Brasil em empresa distribuidora de energia elétrica, por isso, identificar os fatores que conduziram esta empresa a adotar o ABC, o modelo e os resultados coletados, pode contribuir no sentido de conhecer a aplicabilidade do método neste ramo de atividade, inclusive considerando os passos seguidos. Poderá também servir de modelo para as demais empresas do ramo no país que possam vir a desejar seguir os passos da Coelba.

O objetivo geral da pesquisa é verificar que fatores contribuíram para a implantação do $A B C$, qual modelo foi adotado e os resultados percebidos pela Coelba. Os objetivos específicos são: a) Identificar os fatores iniciais que conduziram a Coelba à escolha e adoção do Custeio Baseado em Atividades; b) Apresentar o modelo adotado pela Coelba para a implantação do ABC; c) Apresentar os resultados da aplicação do método. 
O Activity Based Costing ( $A B C$ ) na Companhia de Eletricidade do estado da Bahia (Coelba): fatores relevantes para implantação, o modelo e os resultados obtidos Juliano Almeida de Faria, Sonia Maria da Silva Gomes

\section{REFERENCIAL TEÓRICO}

No século $X X$, no campo da contabilidade gerencial, diversos métodos de custeio foram concebidos na tentativa de melhor atribuir os custos aos produtos, apurando-os de forma que melhor atendam as expectativas inerentes a cada empresa. Para efeito deste artigo foram escolhidos os custeios por Absorção, o Variável e o $A B C$, por serem os mais difundidos na literatura, entretanto, o foco principal do artigo versa sobre este último.

No Brasil, o custeio por absorção é aceito pela auditoria como básico e é obrigatório pela legislação para fins de avaliação de estoque. Esta situação coloca as empresas em posição comum de utilização de dois sistemas de custeio, o obrigatório e o alternativo para quando as empresas buscam informações gerenciais diferenciadas. Como este sistema considera a alocação de todos os custos aos bens, mercadorias ou serviços, há a necessidade de rateio dos custos indiretos, fato que torna as informações de custos relativamente frágeis, visto que os rateios são alternativas de atribuir os custos aos produtos finais diante da dificuldade de fazê-lo diretamente, conforme prediz a materialidade.

Outro método de custeio também chamado de tradicional é o custeio variável. Neste, os gastos só são reconhecidos como custos quando têm relação direta com o volume de produção, ou seja, considera-se custos dos produtos ou serviços apenas os custos chamados de variáveis, aqueles que variam em caso de alteração no volume produzido. Os demais são reconhecidos como despesas do período, pois ao serem considerados fixos não têm qualquer associação com o volume produzido. Desta forma, elimina-se os rateios dos custos indiretos.

\subsection{O Activity Based Costing (ABC)}

O sistema ABC foi sistematizado por Kaplan e Cooper (1998) nos Estados Unidos, por meio de suas experiências trazidas de estudos de casos desenvolvidos nas empresas Schrader Bellows e John Deere. Gomes (2004), defende que o sistema baseado em análise de atividades oferece um cálculo mais acurado do custo do produto, pois considera que quase todas as atividades de uma empresa existem para suportar a produção e entregar bens e serviços, portanto, devem ser consideradas como custo de produto. Objetiva- se desta forma, fornecer informações mais acuradas e estratégicas sobre a produção de bens ou na prestação de serviços, de modo que as decisões sejam tomadas estrategicamente. 
O Activity Based Costing ( $A B C$ ) na Companhia de Eletricidade do estado da Bahia (Coelba): fatores relevantes para implantação, o modelo e os resultados obtidos Juliano Almeida de Faria, Sonia Maria da Silva Gomes

Como parte do processo evolutivo advindas de questões ainda não respondidas e após algumas adequações, Kaplan e Cooper (1998) consideram o ABC como um sistema que oferece às empresas um mapa econômico de suas operações, revelando o custo existente, o projetado de atividades e processos de negócios, o qual esclarece o custo e a lucratividade de cada produto, serviço, cliente e unidade operacional. Esta abordagem, também chamada de segunda versão do ABC (JONES; DUGDALEB, 2002 apud GOMES, 2004), tem como característica principal custear processos, e estes são interdepartamentais, pois podem acontecer em diversos departamentos fazendo uso de recursos de diversos centros para execução de uma atividade.

De acordo com a abordagem de Kaplan e Cooper (1998), o ABC pode ser desenvolvido em quatro etapas, como segue:

- Etapa 1 - desenvolver o dicionário próprio de atividades;

- Etapa 2 - determinar quanto a organização está gastando em cada uma de suas atividades;

- Etapa 3 - identificar produtos, serviços e clientes da organização;e

- Etapa 4 - selecionar geradores de custo da atividade que associam os custos da atividade aos produtos, serviços e clientes da organização.

Estas etapas principais resumem o modelo de implantação do $A B C$ segundo Kaplan e Cooper (1998). Constituem uma referência para empresas que desejam implantar o sistema desde que julguem que este atenderá a demanda por informações de acordo com o ramo de atividade.

Além do modelo apresentado, Brimson (1996) define como Contabilidade por Atividades, o modo de uma empresa investir seu tempo e os recursos para melhorar o gerenciamento estratégico, visando atingir seus objetivos planejados. Segundo este autor, a Contabilidade por Atividades (CPA) é um processo de acumulação e rastreamento de custos e de dados de desempenho para as atividades da empresa, o que proporciona feedback dos resultados reais frete ao custo planejado, para iniciar ações corretivas sempre que necessário. Acrescente-se ainda que a CPA fornece informações para gerenciar as atividades, permitindo conhecer o custo da atividade, o volume de sua produção (medida da atividade) e o desempenho da atividade (indicador de performance).

No Brasil, outra abordagem sobre o ABC foi levantada por Nakagawa (1994), na qual o autor afirma que se trata de uma metodologia desenvolvida para facilitar a análise estratégica de custos relacionados com as atividades que mais impactam o consumo de 
O Activity Based Costing (ABC) na Companhia de Eletricidade do estado da Bahia (Coelba): fatores relevantes para implantação, o modelo e os resultados obtidos Juliano Almeida de Faria, Sonia Maria da Silva Gomes

recursos de uma empresa. De modo diferenciado, o autor afirma que na empresa os recursos são consumidos por suas atividades, e não pelos produtos que esta fabrica, sendo os produtos e serviços uma consequência da execução das atividades, essenciais para produção. O objetivo, assim, passa a ser rastrear as atividades consideradas estritamente relevantes, buscando planejar e racionalizar o uso dos recursos disponíveis para execução das atividades.

\subsection{Pesquisas Recentes}

O setor elétrico no Brasil, desde que passou pela recente reestruturação na década de 1990, passou a ser regulado pela ANEEL, que exige rígida fiscalização e controle com influência direta nos custos de suas empresas. Hungarato e Sant'anna (2005) apresentam as alterações necessárias para aplicação do $A B C$ em uma empresa desta natureza analisando a estruturação dos processos, tarefas, atividades e propuseram direcionadores de custos e objetos de custo. Esta proposta tornou-se relevante e adequada, pois as empresas de energia elétrica caracterizam-se por apresentar diferentes processos com consequente elevação de custos indiretos. Este ambiente é propício ao $A B C$, que visa rastreálos nas diferentes atividades e contribui com informações do processo para tomada de decisão, inclusive de orçamento, atribuindo-lhe uma visão preditiva baseada em atividades.

A partir da metodologia do ABC, Rosa (2006) apresentou uma proposta de modelo para indicadores de desempenho baseados em atividades. Focando nos serviços de manutenção numa indústria foi apresentada uma alternativa para a gestão deste setor que presta serviços à atividade principal de fabricação. Após a validação estatística dos indicadores propostos, o trabalho mostra que o uso destas ferramentas poderá promover ganhos significativos nas relações de cooperação das funções de manutenção e produção, justamente por entender que o desempenho das atividades transpassam os limites dos setores envolvendo diversos departamentos. Neste caso, a cooperação entre setores e o uso da metodologia viabilizaram a identificação e redução de custos não conhecidos anteriormente num setor de manutenção.

O estudo testa o Time- Driven $A B C$ Model que usa o tempo como único direcionador de custos das atividades (KAPLAN; ANDERSON, 2007). Revela que o novo modelo apresenta simplificação dos processos, fato que pode contribuir para viabilizar o uso em um número maior de empresas e, possivelmente, com menor custo. Por fim, outro aspecto 
O Activity Based Costing ( $A B C$ ) na Companhia de Eletricidade do estado da Bahia (Coelba): fatores relevantes para implantação, o modelo e os resultados obtidos Juliano Almeida de Faria, Sonia Maria da Silva Gomes

relevante na pesquisa é o fato de que o baixo índice de implementação destas ferramentas pode ser decorrente de fatores como deficiência na compreensão do $A B C$, falta de discernimento sobre o modelo de negócios da empresa e a dinâmica dos seus custos (DALMÁCIO; AGUIAR; REZENDE, 2007). Portanto, nota-se que a alteração na metodologia dos direcionadores pode contribuir mas, possivelmente, não será a solução definitiva para a maximização do uso do modelo, pois é necessário entender aspectos mais abrangentes da empresa, independente do modelo a ser abordado como aspectos sociais, por exemplo, campo em que a teoria institucional poderá contribuir.

\section{METODOLOGIA}

Foi realizado estudo de caso na Coelba que concretizou a implantação do sistema de custeio baseado em atividades e que já colhe resultados desta opção estratégica. A pesquisa caracteriza-se como qualitativa descritiva e permeia este estudo de caso que será utilizado por permitir o aprofundamento do estudo do fenômeno vislumbrando a completude, na medida do possível, e observando as relações com o ambiente. Martins (2006) esclarece que no estudo de caso são pesquisados fenômenos considerando o seu contexto real, tendo o pesquisador pouco controle tanto em relação aos eventos quanto sobre manifestações do fenômeno. Uma pesquisa documental aliada a entrevistas com os funcionários que fizeram parte do grupo de planejamento inicial da implantação da metodologia, visa identificar como nasceu a necessidade de implantação de um novo sistema de custeio, quais as características do modelo implantado e os resultados deste processo.

No total, 34 funcionários participaram da implantação do projeto em todas as gerências da empresa em diversos níveis. Todos foram entrevistados mediante o uso de entrevistas estruturadas que foram realizadas na própria empresa com duração média de 20 minutos para cada funcionário, tempo em que questionários foram preenchidos.

O questionário foi dividido em três partes de modo a atender aos objetivos específicos deste artigo, a saber: Fatores relevantes para implantação do Custeio Baseado em Atividades - ABC, o modelo adotado pela Coelba, resultados da aplicação do método. Cada parte foi composta com uma sequência de afirmações em que os mesmos foram solicitados a posicionar-se sobre a veracidade daquela afirmação para a Coelba. Diante da afirmativa haviam as opções "Concordo", "Indiferente" e "Discordo".

O trabalho in loco visou facilitar a coleta de dados e garantir a correta interpretação do 
O Activity Based Costing (ABC) na Companhia de Eletricidade do estado da Bahia (Coelba): fatores relevantes para implantação, o modelo e os resultados obtidos Juliano Almeida de Faria, Sonia Maria da Silva Gomes

questionário pelos entrevistados, de modo a evitar vieses cognitivos. Desta forma, foi possível manter o registro histórico para possíveis pesquisas futuras que desejem partir deste ponto.

A análise descritiva dos questionários apresentou a confluência de respostas dentro de uma linha de tendência. Foram consideradas as respostas identificadas nos questionários que por sua vez apontavam um dos três itens supracitados, independente dos setores e cargos aos quais os respondentes ocupavam.

\section{ANÁLISE E DISCUSSÃO DOS RESULTADOS DA PESQUISA}

Segundo dados coletados na pesquisa, quatro funcionários foram responsáveis pela elaboração do projeto de implantação por determinação da diretoria da empresa. A equipe multidisciplinar, formada por um doutor em engenharia de produção (gestor), um mestre em administração (analista), um contador (gestor) e um economista (analista), contribuiu para elaboração de um projeto com maiores chances de aplicabilidade. Esta equipe foi mantida e acompanha o projeto desde sua implantação, ocorrida no início de 2007. Esta estrutura de investimento no sistema, segundo dados da pesquisa, contribuiu significativamente para o sucesso esperado do $A B C$ na Coelba.

\subsection{Parte I - Fatores e Resultados}

O fatores relevantes que conduziram a Coelba à escolha e adoção do Custeio Baseado em Atividades foram identificados e estão dispostos Quadro 1. Também neste quadro, com as respectivas marcações com um " $x$ " na coluna denominada de Resultado, é possível constatar quais dos fatores identificados inicialmente se confirmaram em resultados na Coelba. 
O Activity Based Costing (ABC) na Companhia de Eletricidade do estado da Bahia (Coelba): fatores relevantes para implantação, o modelo e os resultados obtidos Juliano Almeida de Faria, Sonia Maria da Silva Gomes

Quadro 1 - Comparativo de fatores motivacionais para implantação versus resultados

\begin{tabular}{|c|c|c|c|}
\hline N. & Item & Fator & $\begin{array}{c}\text { Resultad } \\
\text { o }\end{array}$ \\
\hline 1 & $\begin{array}{l}\text { O ABC proporciona conhecer o custo aproximado de cada atividade e desta forma } \\
\text { é possível elaborar previsões com maior grau de certeza; }\end{array}$ & $\bar{X}$ & $\mathrm{X}$ \\
\hline 2 & $\begin{array}{l}\mathrm{O} A B C \text { contribui para melhorar a qualidade, pontualidade e eficiência das } \\
\text { atividades que executam; }\end{array}$ & $\mathrm{X}$ & $\mathrm{X}$ \\
\hline 3 & $\begin{array}{l}\text { O sistema ABC mensura com certa acurácia o custo e a lucratividade de cada } \\
\text { serviço produtos e cliente da empresa; }\end{array}$ & $\mathrm{X}$ & $\mathrm{X}$ \\
\hline 4 & Informações gerenciais relativamente mais fidedignas por meio da redução do rateio; & $\mathrm{X}$ & $\mathrm{X}$ \\
\hline 5 & Proporciona melhor visualização dos fluxos dos processos; & $\mathrm{X}$ & $\mathrm{X}$ \\
\hline 6 & $\begin{array}{l}\text { Identifica, de forma mais transparente, onde os itens em estudo estão } \\
\text { consumindo mais recursos; }\end{array}$ & $\mathrm{X}$ & $\bar{X}$ \\
\hline 7 & $\begin{array}{l}\text { Pode fornecer subsídios para gestão econômica, custo de oportunidade e custo } \\
\text { de reposição; }\end{array}$ & $\mathrm{X}$ & $\mathrm{X}$ \\
\hline 8 & Possibilita a identificação das atividades que não agregam valor ao produto; & $\mathrm{X}$ & $\mathrm{X}$ \\
\hline 9 & $\begin{array}{l}\text { O ABC proporciona conhecer o custo aproximado de cada atividade e desta forma } \\
\text { é possível gerar previsões com maior grau de certeza; }\end{array}$ & $\bar{X}$ & $\mathrm{X}$ \\
\hline $\begin{array}{l}1 \\
0\end{array}$ & $\begin{array}{l}\text { O custeio realizado antes do } A B C \text { não relatava com precisão o custo de } \\
\text { processos, produtos e clientes; e }\end{array}$ & $\mathrm{X}$ & $\mathrm{X}$ \\
\hline $\begin{array}{l}1 \\
1\end{array}$ & $\begin{array}{l}\text { O sistema ABC define prioridade para atividades de aprimoramento de processos } \\
\text { e ajudam os gerentes a tomar decisões estratégicas. }\end{array}$ & $\mathrm{X}$ & $\mathrm{X}$ \\
\hline $\begin{array}{l}1 \\
2\end{array}$ & $\begin{array}{l}\text { É possível identificar o custo de cada atividade mapeada e traçar metas previstas } \\
\text { em orçamento }\end{array}$ & & $\bar{X}$ \\
\hline $\begin{array}{l}1 \\
3\end{array}$ & $\begin{array}{l}\text { Associar o ABC ao orçamento possibilitou o controle efetivo do fluxo financeiro uma } \\
\text { vez que é fácil identificar qual atividade não está cumprindo com o planejado }\end{array}$ & & $\mathrm{X}$ \\
\hline $\begin{array}{l}1 \\
4\end{array}$ & $\begin{array}{l}\text { A Coelba passou a usufruir do feedback útil destinado a aperfeiçoar os processos de } \\
\text { negócios por meio de aprendizado e aprimoramento contínuo com foco no } \\
\text { planejamento estratégico }\end{array}$ & & $\mathrm{X}$ \\
\hline $\begin{array}{l}1 \\
5\end{array}$ & $\begin{array}{l}\text { A empresa passou a identificar os custos ambientais das atividades melhorando o } \\
\text { fluxo de informações para decisões. }\end{array}$ & & $\mathrm{X}$ \\
\hline
\end{tabular}

Trata-se de uma comparação que mostra quais dos resultados obtidos pela Coelba foram projetados como fatores que motivaram a empresa a adotar o $\mathrm{ABC}$. Desta forma, os fatores citados foram relevantes para a aplicação de uma metodologia de cunho gerencial a fim de dispor de informações de um sistema de custeio alternativo ao exigido por lei. Além disso, conforme dados da pesquisa, pode-se destacar que a participação qualitativa da equipe de planejamento do sistema, cujas características como nível de formação e interdisciplinaridade denotam nível de formação esperada pela empresa para escolha do sistema que mais reunisse condições para satisfazer as necessidades levantadas naquele momento.

Todos os gerentes passaram a receber com frequência mensal relatórios como de custos (orçados versus realizados) por cada uma das atividades dos processos, custos unitários dos processos e custos unitários por Regional. Este novo mapeamento forneceu aos tomadores de decisão maiores informações acerca dos processos aos quais estavam envolvidos. 
O Activity Based Costing (ABC) na Companhia de Eletricidade do estado da Bahia (Coelba): fatores relevantes para implantação, o modelo e os resultados obtidos Juliano Almeida de Faria, Sonia Maria da Silva Gomes

Segundo dados da pesquisa, além dos resultados que já são percebidos pela Coelba, a aplicação do $A B C$ às atividades que geram impacto ambiental tem proporcionado conhecimento para que seja possível conhecer o custo ambiental daquela atividade específica. Esta informação tem sido considerada relevante visto que já é possível apurar custos relacionados a atividades de alto impacto sócio-ambiental. Este passo representa a preocupação da empresa com o meio ambiente no qual se encontra e mantém hoje oito grupos de trabalho específicos para redução de custos baseados em atividades, sendo que um destes trabalha exclusivamente voltado para o meio ambiente.

Ainda, conforme dados da pesquisa, foi identificado que o $A B C$ proporcionou mais resultados que o esperado, superando expectativas dos gestores e diretoria. Este aspecto é positivo, pois de segundo dados da pesquisa está relacionado com o tipo de modelo utilizado pela Coelba e representa a nova visão sobre o mesmo processo trazendo maiores informações para tomada de decisões estratégicas, uma vez que o sistema está totalmente alinhado com o plano estratégico da empresa.

\subsection{Parte II - Características do Modelo}

Por fim, esta parte do questionário visou identificar e apresentar características do modelo implantado na Coelba. Seguindo uma abordagem filosófica alinhada com a gestão de processos ( Total Quality Management - TQM) e MEG (modelo de excelência em gestão da FNQ),(KAPLAN; COOPER, 1998), a Coelba realizou a implantação do sistema ABC nas seguintes etapas:

1. Consolidação do mapa de processos;

2. Definição das atividades que caracterizam despesas e investimentos;

3. Definição dos centros de custos;

4. Adequação do sistema SAP/R3 (Sistema contábil interno);

5. Treinamento das áreas;

6. Divulgação da nova estrutura e implantação.

Apesar de não ter seguido um modelo específico, a equipe de implantação baseou-se na literatura existente e traçou a própria sistemática. Esta adaptação rendeu à Coelba os resultados tratados adiante. Matos (2006 apud DALMÁCIO; AGUIAR; REZENDE, 2007), destaca que o problema do $A B C$ não se restringe somente à sua complexidade, mas no fato de tratar a implementação desse método como se estivesse seguindo um 
O Activity Based Costing ( $A B C$ ) na Companhia de Eletricidade do estado da Bahia (Coelba): fatores relevantes para implantação, o modelo e os resultados obtidos Juliano Almeida de Faria, Sonia Maria da Silva Gomes

receituário. Conforme dados da pesquisa, a Coelba não seguiu receituários existentes conforme afirmam os autores, mas baseia sua estrutura na metodologia traçada por Kaplan e Cooper (1998).

A equipe buscou identificar as características da empresa, buscou uma adequação mútua, de modo que nem o modelo nem a empresa fossem radicalmente modificados para atingir o objetivo. De acordo com dados da pesquisa, este aspecto contribuiu neste processo, pois foi possível identificar com mais clareza as expectativas, dificuldades e necessidades inerentes a esta fase.

As principais dificuldades encontradas para a implantação do $A B C$ foram a existência de cultura de gestão departamental (funcional), que se apresentou resistente à mudança, e falta de conhecimento sobre gestão de custos por atividades. Para solucionar estes problemas, diversos treinamentos de formação sobre a metodologia foram aplicados, voltados a apresentar os benefícios esperados para toda a empresa e a estrutura de funcionamento do sistema.

Além disso, a Coelba implantou um sistema de remuneração variável para os funcionários em vários níveis baseado nas informações do $A B C$, e apontava melhores resultados para os setores e funcionários que melhor assimilassem as caractetísticas da metodologia e cumprissem com as ações propostas para implantação nos respectivos setores e funções. Com isso, houve motivação adicional para apoiar a implantação do sistema de modo a fazer jus aos prêmios ofertados.

As características identificadas no modelo adaptado à Coelba são:

1. Obriga a implantação, permanência e revisão de controles internos baseados em atividades;

2. Pode ser um sistema paralelo ao sistema de contabilidade;

3. Os relatórios financeiros não eram suficientes para suprimento adequado de informações estratégicas gerenciais;

4. Atribuem os custos de utilização de recursos aos objetos de custo;

5. A Coelba conhece quanto está gastando em cada uma das suas atividades;

6. Foram identificados os custos de cada produto, serviço e cliente/segmento da Coelba com base na nova metodologia;

7. Foram identificados direcionadores de custos suficientes para associar recursos aos objetos de custo passando pelas atividades;

8. $O A B C$ da Coelba foi concebido com completo alinhamento com 0 
O Activity Based Costing (ABC) na Companhia de Eletricidade do estado da Bahia (Coelba): fatores relevantes para implantação, o modelo e os resultados obtidos Juliano Almeida de Faria, Sonia Maria da Silva Gomes

planejamento estratégico;

9. $\mathrm{O} A B C$ é utilizado com base para o orçamento organizacional. Desta forma é possível atuar em caráter preditivo de gastos futuros;

10. O custeio padrão é utilizado na empresa concomitantemente ao ABC;

11. O sistema de custeio financeiro tradicional (conforme legislação) foi mantido;e

12. Avaliações especializadas destinadas a fornecer feedback para aprendizado e aprimoramento operacional são realizadas periodicamente.

As características identificadas atribuem ao modelo personalidade própria no que tange aplicabilidade e necessidades específicas da Coelba, a exemplo do item 1, o qual é compartilhado também por Nakagawa (1994), que ressalta o efeito comportamental do ABC ao demandar a implantação, permanência e revisão de controles internos baseados em atividades. Cita-se também o item 13, citado por Brimson (1996), o qual apresenta o feedback como uma peça importante para que seja possível iniciar ações corretivas sempre que necessário.

A despeito das contribuições de diversos autores na construção do modelo e da participação da equipe de implantação, o modelo adotado pela Coelba não se torna inválido, pois segundo Dalmácio,Aguiar e Rezende (2007), o modelo pode sofrer adaptações desde que sejam para adaptar-se às necessidades da empresa e que resultados positivos possam ser coletados por meio deste. Este processo aconteceu com a Coelba, visto que as necessidades foram corretamente levantadas e adaptou- se o modelo ao foco escolhido respeitando as peculiaridades inerentes à organização.

Algumas características não encontradas no modelo são as seguintes:

1. Existe um sistema informatizado exclusivo para o $A B C$.

2. O sistema informatizado foi desenvolvido internamente.

3. Houve contratação de consultoria externa para implantação do ABC.

4. $O A B C$ utiliza dados do sistema contábil tradicional para alimentar o sistema próprio.

5. No que tange o $A B C$, a Coelba realiza benchmarketing com outras companhias elétricas no Brasil.

Apesar destas características do modelo da Coelba estarem ausentes no modelo de Kaplan e Cooper (1998), em nada prejudicam o modelo visto que os resultados encontrados servem de suporte empírico para avaliação da viabilidade da forma em que o $A B C$ foi adotado na Coelba. Novas ações podem ser adotadas junto ao modelo do $A B C$, entretando não foram 
O Activity Based Costing (ABC) na Companhia de Eletricidade do estado da Bahia (Coelba): fatores relevantes para implantação, o modelo e os resultados obtidos Juliano Almeida de Faria, Sonia Maria da Silva Gomes

opção da Coelba.

\section{CONSIDERAÇÕES FINAIS}

A Coelba adotou o sistema $A B C$ com o principal objetivo de redução de custos nos seus processos internos. Decidiu fazê-lo de forma estruturada, utilizando as ferramentas disponíveis no mercado e na literatura. Uma equipe multidisciplinar foi responsável por todo estudo, planejamento, implantação e acompanhamento do processo. Esta característica foi um diferencial para que os resultados do método fossem positivos, pois demonstra a intenção e apoio do corpo gestor da empresa em reduzir custos sem prejudicar as estruturas e ainda melhorando a qualidade dos processos internos.

A estrutura interna montada pela Coelba permitiu o levantamento de outras necessidades da empresa, ou seja, foi possível fazer uma leitura dos fatores que contribuíam para a adoção de um sistema gerencial alternativo, neste caso o $A B C$, além da redução de custos. Desta forma, atribuiu-se ao sistema características que pudessem proporcionar o atendimento das demais necessidades por meio de uma metodologia $A B C$ pautadas principalmente nas idéias de Kaplan e Cooper (1998), porém permitiu influenciar-se por contribuições de demais autores. O modelo adotado pela Coelba atendeu as necessidades e ainda apresentou resultados além dos esperados inicialmente.

O quadro atual do $A B C$ na Coelba é promissor visto que as bases do sistema foram bem estabelecidas, a estrutura de formação da nova cultura de controle e gestão de recursos por atividades foi absorvida pelos gestores que fazem uso dos relatórios fornecidos pelo $A B C$. A gestão tem conseguido mensurar o custo das atividades que inclusive causam impacto ambiental representando uma inovação em empresas deste setor no Brasil.

Observa-se que a adoção de uma nova metodologia como o $A B C$ demanda mais que o segmento das etapas trilhadas por autores na literatura, carece de um envolvimento completo da empresa em todos os níveis, disposição para investir de forma ordenada e estratégica com engajamento total da equipe de trabalho. De modo adicional, a perspectiva da adequação da metodologia de acordo com as necessidades da empresa é mais um fator positivo, pois demonstra flexibilidade sem prejuízos à eficiência dos resultados apresentados pelo sistema de custeio ABC.

Sugere-se o estudo da implantação do $A B C$ na Coelba sob a ótica da teoria institucional, avaliando os demais aspectos sociais e institucionais que compartilham deste 
O Activity Based Costing (ABC) na Companhia de Eletricidade do estado da Bahia (Coelba): fatores relevantes para implantação, o modelo e os resultados obtidos Juliano Almeida de Faria, Sonia Maria da Silva Gomes

processo. Este artigo é uma pesquisa baseada na literatura e no estudo de caso da Coelba, sua aplicação prática está limitada as atividades desenvolvidas em uma empresa com características semelhantes. Assim, não se pode garantir que os resultados do método serão idênticos em empresas nos demais setores da economia, mas poderá servir de exemplo para outras empresas distribuidoras de energia elétrica. Por objetivar identificar os fatores que levam a escolha do método, o modelo e os resultados, o artigo limitou-se a estes fins, podendo-se aprofundar o estudo a partir deste ponto envolvendo outros fatores que possam ser significativos.

\section{Referências}

ABRANTES, Francianne M. Gama de; MARIOTO, Sérgio Luiz. Método de custeio baseado na atividade - ABC. Revista de Ciências Gerenciais, Vol. XII, n. 1ㅣ, ano 2008.

AGÊNCIA NACIONAL DE ENERGIA ELÉTRICA. Disponível em: HTTP://www.aneel.gov.br>. Acesso em: 06 jul. 2009.

ANDRADE, Nilton de A.; BATISTA, Daniel G.; SOUSA, Cleber B.de. Vantagens e desvantagensda utilização do sistema de custeio ABC. Disponível em: $\quad$ http://www.mendeley.com/c/26072324/Andrade-OVantagens-e-desvantagens-dautilizao-do- sistema-de-custeio-abc. Business Administration on Mendeley. Acesso em: 18 jun. 2009.

BRIMSON, James A. Contabilidade por atividades: uma abordagem de custeio baseado em atividade. São Paulo: Atlas, 1996.

CARVALHO, Cleverton Euclen; MIRANDA, Gilberto J.; MARTINS, Vidigal F.; FARIA, Adolar F. de. Custeio ABC no ambiente hospitalar: um estudo nos hospitais universitários e de ensino brasileiros. $\quad X$ Congresso Internacional de Custos. Anais... Lyon, França, de 13 a 15 de junho/2007.

COLAUTO, Romualdo; Marlei Salete MECCA; Claide VANZELLA. Gerenciamento baseado em atividades: aplicação em uma distribuidora de energia elétrica. XIV Congresso Brasileiro de Custos. Anais... João Pessoa - PB, Brasil, 05 de dezembro a 07 de dezembro de 2007.

COMPANHIA DE ELETRICIDADE DO ESTADO DA BAHIA. Disponível em: HTTP://www.coelba.com.br>. Acesso em: 06 jul. 2009.

DALMÁCIO, Flávia Zóboli; AGUIAR, Andson Braga de; REZENDE, Amaury José. Uma aplicação do time-driven abc model no setor de serviço hospitalar: a nova abordagem do abc proposta por Kaplan e Anderson. Contabilidade Vista \& Revista, v. 18, n. 2, p. 11-34, abr./ jun. 2007.

GARRISON, Ruy H.; NOREEN, Eric W. Contabilidade Gerencial. Tradução José Luiz Paravato. 9 a Ed. Rio de Janeiro: LTC, 2001.

GERI, Nitza; RONEN, Boaz. Relevance lost: the rise and fall of activity-based costing. Human Systems Management, 24 (2005) 133-144 133 IOS Press.

GOMES, Sônia Maria da S. Um sistema de contabilidade por atividades para a gestão de empresas de serviços em desenvolvimento de software. Tese de Doutorado. UFSC - 
O Activity Based Costing (ABC) na Companhia de Eletricidade do estado da Bahia (Coelba): fatores relevantes para implantação, o modelo e os resultados obtidos Juliano Almeida de Faria, Sonia Maria da Silva Gomes

Florianópolis - SC, 2004.

HUNGARATO, Arildo. SANT'ANNA Dimitri. Activity Based Costing (ABC) para empresas de distribuição de energia elétrica no Brasil: uma proposta de aplicação. IX Congresso Internacional de Custos. Anais... Florianópolis, SC, Brasil - 28 a 30 de novembro de 2005.

KAPLAN, Robert S.; ANDERSON, Steven R. Custeio baseado em atividade e tempo. Tradução de Afonso Celso da Cunha Serra. Rio de Janeiro: Elsevier, 2007.

KAPLAN, Robert S.; COOPER, Robin. Custo e desempenho: administre seus custos para ser mais competitivo. Tradução de O.P. Traduções. São Paulo: Futura, 1998.

MARTIN, Nilton Cano. Da Contabilidade à Controladoria: a Evolução Necessária. Revista Contabilidade \& Finanças. USP, São Paulo, n. 28, p. 7 - 28, jan./abr. 2002.

MARTINS, Eliseu. Contabilidade de custos. 9a ed. São Paulo: Atlas, 2008.

MARTINS, Gilberto de Andrade. Estudo de Caso: Uma Estratégia de Pesquisa. São Paulo: Atlas, 2006.

NAKAGAWA, Masayuki. ABC: custeio baseado em atividades. São Paulo: Atlas, 1994.

PINTO, Alfredo A. Gonçalves; LIMEIRA, André L.F.; SILVA, Carlos Alberto dos S.; COELHO, Fabiano S. Gestão de Custos. 2a Ed. Rio de Janeiro: Editora FGV, 2008.

QUEIROZ, Antônio Diomário de; COSTA, Renato; GOMES, Sônia Maria da S.. O ABC em uma empresa de desenvolvimento de software: um estudo de caso. Revista Contemporânea de Contabilidade, ISSN 1807-1821, Vol. 1, No. 1, 2004 , p. 29-44.

ROSA, Eurycibiades Barra. Indicadores de desempenho e sistema ABC: o uso de indicadores para uma gestão eficaz no custeio e das atividades de manutenção. Tese (Doutorado). Escola Politécnica da USP. São Paulo, 2006.

SCUSSIATTO, Angelo Cesar; VANZELLA, Clailde. Contabilidade por Atividades: a implantação em empresa brasileira distribuidora de energia elétrica. IX Congresso Internacional de Custos. Anais... Florianópolis, SC, Brasil - 28 a 30 de novembro de 2005.

VANZELLA, Clailde. Metodologia para implantação da contabilidade por atividades em empresas distribuidoras de energia elétrica. Dissertação de Mestrado - UFSC, Florianópolis, SC, 2003. 